\title{
The forecasting of tornado events: the synoptic background of two different tornado case studies
}

\author{
Barbara Wrona \\ Institute of Meteorology and Water Management, National Research Institute, Branch in Wrockaw, 51-616 \\ Wrockaw,Parkowa Street 30,Poland, e-mail: barbara.wrona@imgw.pl,wro777@gmail.com
}

\author{
Zanita Avotniece \\ Latvian Environment, Geology and Meteorology Centre (LEGME), LV-1019 Riga, Maskavas Street 165, \\ Latvia,e-mail: zanita.avotniece@lvgmc.lv
}

\begin{abstract}
The synoptic analyses of two different tornado cases, observed in Latvia and Poland in the summer of 2012, are examined in this paper. The first of them, the tornado in Latvia seemed to be a "textbook example" of tornado occurrence. Its development took place in the contact zone of the warm, tropical air, characterized by a very high CAPE (Convective Available Potential Energy), with cold and moist polar marine air mass behind the convergence line that determined very good conditions for convective updraft. Additionally, the moderate environmental wind shear favoured the sufficient condition for concentrating the atmosphere's vorticity into well-organized strong rotating upward motions that produced the supercell structures and tornado. Thus, from the forecaster's point of view, the occurrence of this severe convective event was not a surprise. This phenomenon was predicted correctly more than a dozen hours before the tornado occurred.

The second event occurred in the north of Poland and was associated with a thunderstorm where a supercell was formed in conditions of low CAPE but favourable wind profile, both vertical and horizontal. Helical environments (characterized by large shear vectors that veered with height in the lowest three kilometres, especially the nearest one kilometre) were arguably the most important factor that determined the Polish tornado's occurrence. In this case the analysis of the synoptic situation was not so clear and the superficial analysis, even post factum, regarding radar, satellite or detection maps might have suggested "quite a normal" summer thunderstorm. However, the detailed examination showed the reasons why tornado genesis took place. The potential conditions for the occurrence of this severe phenomenon were indicated by forecasters, although the forecasts were less exact with regard to the place of occurrence and the heaviness of the strike.
\end{abstract}

Keywords: tornadoes, synoptic background, forecasting, nowcasting

Submitted 24 September 2014, revised 10 March 2015, accepted 25 May 2015

\section{Introduction}

Tornadoes are often the subject of in-depth stu-dies and extensively discussed in scientific literature (Maddox et al. 1980; Brooks, Doswell 2001; Dotzek 2003; Marcinoniene 2003; Setvák et al. 2003; Davies-Jones 2006; Agee, Jones 2009; Wurman et. al. 2010; Brazdil et al. 2012; Rauhala et al. 2012). This paper presents a synoptic analysis of two examples of this phenomenon which, although occurring in relatively different weather conditions, caused equally disas-trous consequences. The first discussed tornado, called locally "virpulstabs", was noted in Latvia on July 29, 2012, and the second was the whirlwind in Poland which occurred two weeks earlier, on July 14, 2012. The synoptic conditions which produced the tornado in Latvia were a quite typical example of convective weather connected with a warm sector ahead of the cold front preceded by a convergence line, except for the fact that the area of positive vorticity advection was neutral or just slightly positive, which, from a theoretical point of view (Gold, Nielsen-Gammon 2008; Schumann, Roebber 2010), is one basic component for tornado initiation. The question is, what was the compensation for this? The second event occurred in the north of Poland and was associated with a supercell when the weather situation preceding the tornado was far from what seemed to be "favourable conditions" for tornado genesis. It was related to a shallow, eastwardly moving cold front with relatively low cloud cover, towered by the supercell that spawned the tornado. Its scale of damage was measured between the F2 and F3 rating, according to ESWD (European Severe Weather Data). A detailed synoptic analysis, containing both the large-synoptic scale as well as the detailed mesoscale analysis of these two similar (in terms of 
process) and yet different (in terms of origin) extreme meteorological phenomena aims to identify common features crucial for their formation.

\section{Synoptic Backgrounds}

There are many case studies that reveal similar synoptic preconditions for the formation of tornadoes. Some main synoptic flow patterns favourable for the occurrence of a tornado have been distinguished: upper-level trough the west of the location of the tornado that contributes to deepening of a surface low; sufficient instability commonly associated with the presence of low level moisture in a warm sector; upper level jet streak collocated with a centre of rapid decrease in surface pressure contributing to intensification of the synoptic cyclone; and increasing vertical wind shear (Rotunno, Klemp 1982; Schafer, Doswell 1984; Houze 1993; Corfidi et al. 2010; Mercer et al. 2012). Although the conditions in the larger synoptic scale create a favourable thermodynamic environment, the formation of deep convective phenomena is determined by mesoscale conditions. Three factors are necessary for the development of deep moist convection: low-level moisture, conditional instability and source of lift. Other factors like vertical wind profile may determine the type of convection which forms (Doswell 1987). Helical environments, understood as "ones with large shear vectors that veer with height in the lowest few kilometres" are conducive to tornadoes (Kerr, Darkow 1996; Davies-Jones 2006). Thus, the goal of this paper is to analyse both of these tornado cases by analysing at the conditions in which they developed.

\subsection{Tornado in Latvia, July 29, 2012}

The tornado in Latvia resulted from the formation of a supercell in the conditions of deep convection connected with the slow movement of atrough with a convergence line preceding a cold front (Fig. 1). During the days prior to the event, an extensive warm sector of a cyclone located over the North Sea caused a gradual inflow of warm and humid tropical air from the south which, on July 29, resulted in temperatures as high as $20^{\circ} \mathrm{C}$ at $850 \mathrm{hPa}$ causing maximum surface temperatures to increase up to $33^{\circ} \mathrm{C}$ in many places (Fig. 2).

In the afternoon of July 29, 2012, a shallow trough with a cold front zone was slowly approaching Latvia from the west of Europe, and it waspreceded by a convergence line - this formed a classic scenario for intense convection. At the same time, in the middle and upper troposphere, an extended ridge covered the territory of Eastern Europe.

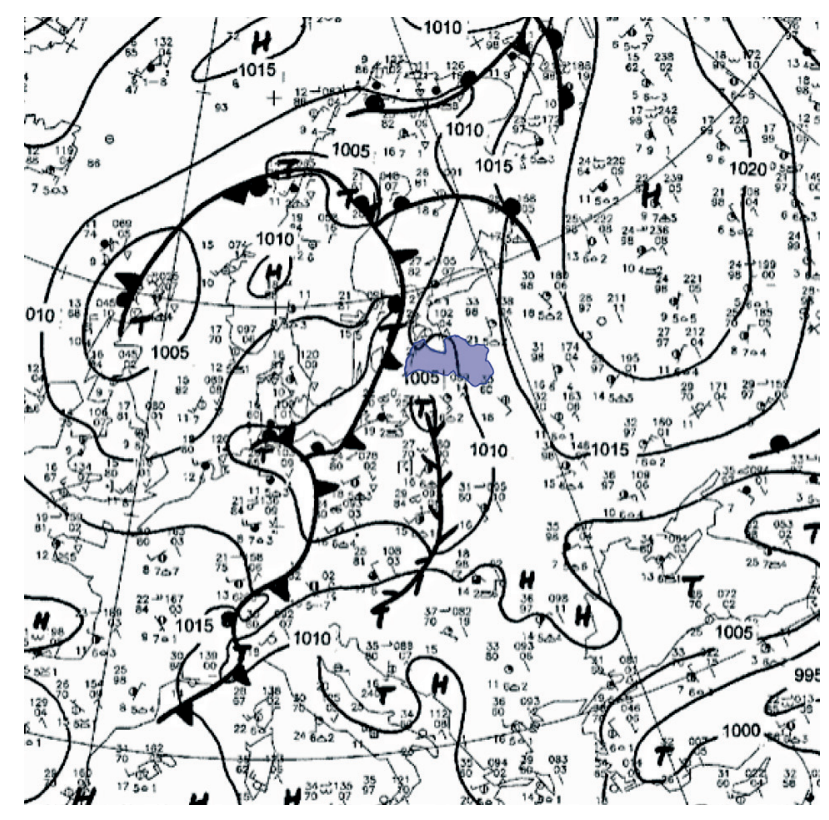

Fig. 1. The surface weather map; July 29, 2012; 12:00 UTC (source: DWD)

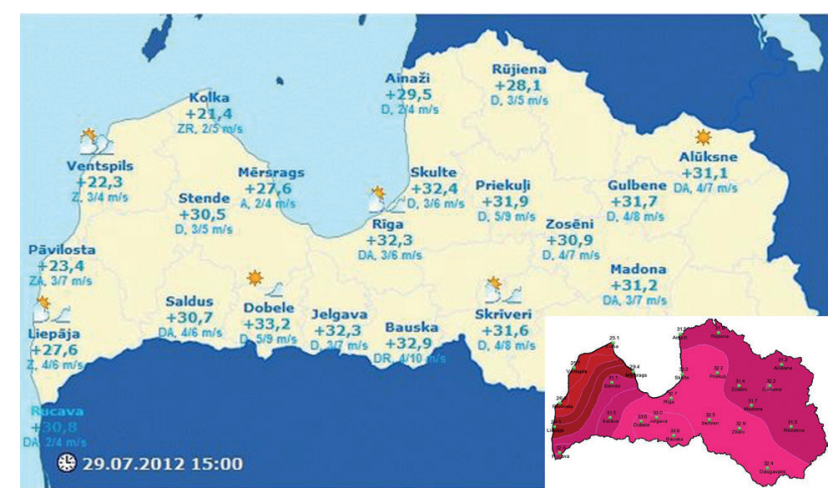

Fig. 2. Temperature and mean wind speed at 15:00 in Latvia; July 29, 2012 (source: LEGMC)

The nearest sounding indicators from Tallinn (Estonia; 29.07.2012 at 00:00 UTC), located almost at the same longitude as Riga, combined with NWP DWD data (Deutscher Wetter Dienst Numerical Model Prediction) showed that instability and low-level humidity conditions were favourable for tornado formation in this region. The specific humi-dity of the warm sector of an air mass that struggled over Latvia was potentially very moist, and oscillated between $12 \mathrm{~g} / \mathrm{kg}$ and $14 \mathrm{~g} / \mathrm{kg}$, which corresponded to mean precipitable water content (PW) of about 34-40 $\mathrm{mm}(\max \mathrm{PW}=44 \mathrm{~mm})$. Convective available potential energy (CAPE) increased up to $2200 \mathrm{~J} / \mathrm{kg}$, the values of lifted index (LI) were also high: $-5^{\circ} \mathrm{C}$. Convective inhibition energy (CIN) decreased totally from $-156 \mathrm{~J} / \mathrm{kg}$ during the 14 hours preceding the occurrence of the tornado. These conditions created a low lifting condensation level (LCL) of about $280 \mathrm{~m}$ AGL. At the vertical wind profile, in the middle and upper troposphere, an almost steady flow from the south $\left(210-220^{\circ}\right)$, with a speed of 
about 36-40 kt, was observed. Despite a lack of vertical shear in the middle troposphere, some veer shear was observed between the surface and $850 \mathrm{hPa}$ level. The wind changed direction and speed, from $090 \% 05 \mathrm{kt}$ near the surface to $220^{\circ} / 25 \mathrm{kt}$ at the height of about $2000 \mathrm{~m}$. This vertical and directional shear in the low level atmosphere, combined with the existing conditions of deep convection, created a favourable basis for the development of vorticity at ground level - a situation conducive to the development of supercells and tornadoes.

The vorticity at $500 \mathrm{hPa}$ and $300 \mathrm{hPa}$ at 12:00 UTC showed that the whole region was in an area of neutral or slightly positive vorticity advection, as mentioned above, in the periphery of the upper ridge. Although there was no significant positive vorticity observed, the strong lowlevel warm advection connected with the high low-level moisture field was big enough to release and sustain the energy needed to maintain upward motion (Maddox et al.

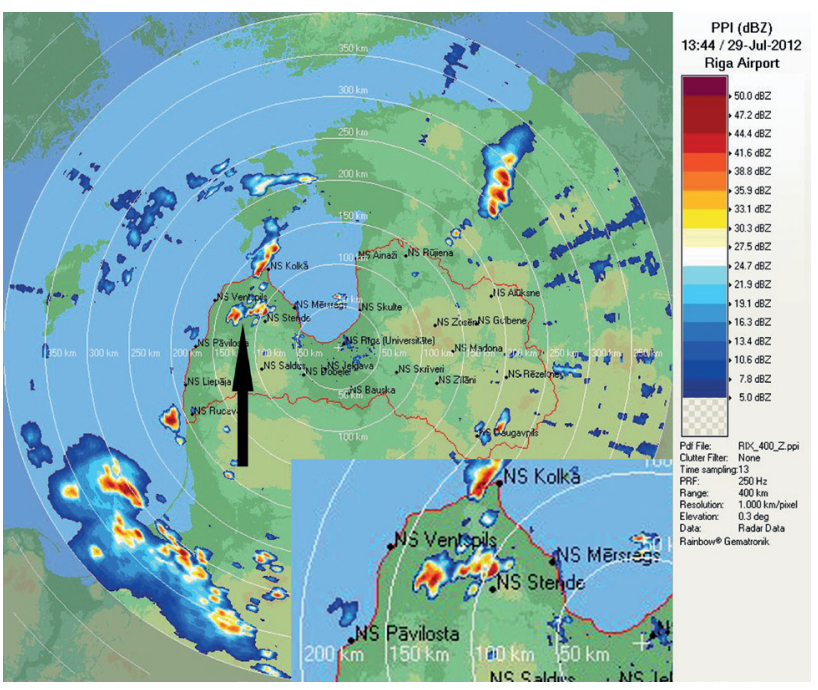

Fig. 3. Dopper-radar data from Latvia, July 29, 2012; PPI: 13:44 UTC. Yellow arrows indicate the supercell's position with hook echo (source: LEGMC)

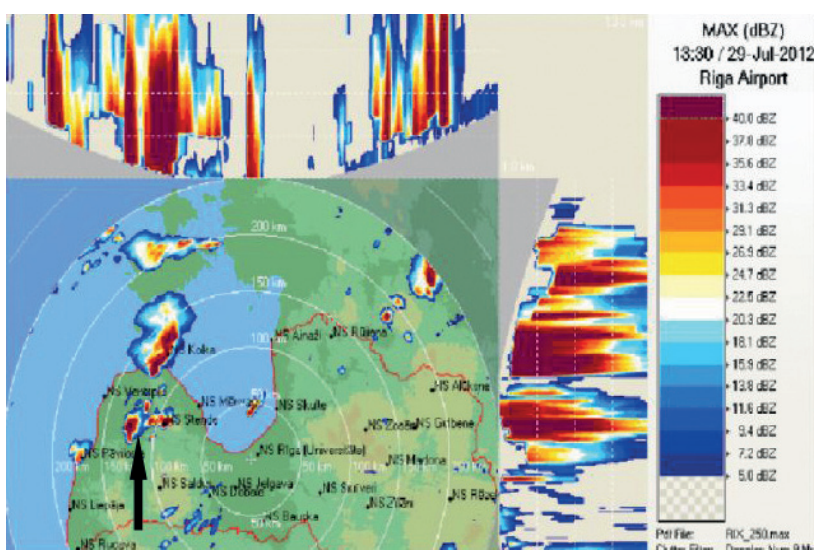

Fig. 4. Dopper-radar data from Latvia, July 29, 2012; MAX CAPPI: 13:30 UTC. Yellow arrow indicates the position of supercell in Talsi region, the most affected by the tornado (source: LEGMC)
1980; Maddox, Doswell 1981; Boustead et al 2013). Moreover, the area of western Latvia remained under the influence of the upper level divergence connected with the right-entrance of a jet stream at $300 \mathrm{hPa}$. The jet was moving to the north above the Baltic Sea and Scandinavia. The upper divergence zone emphasized the upward motion within the lower and middle troposphere and caused an outflow of air in the upper troposphere, thus strengthening the low-level moisture, instability and convergence interaction (Uccelini, Johnson 1979). The mechanism that initiated the upward lifting in the atmosphere was the convergence in the cold front line which was moving over the area of Latvia in the afternoon hours.

The first thunderstorms were noted around 13:00 UTC, however, the main activity developed in the late afternoon, extending mostly over western Latvia. In the afternoon (14:00 UTC) severe thunderstorms with hail, and strong wind gusts at the seaboard of up to $24 \mathrm{~m} / \mathrm{s}$ were noted. At about 13:00 UTC, near Stende meteorological observation station, a huge Cb started to develop. During 20 to $40 \mathrm{~min}$. it converted into a supercell with a hook echo visible with radar imagery (Fig. 3) and then transformed into tornadic thunder. The maximum reflectivity on radar in Riga showed that the tops of clouds exceeded $15 \mathrm{~km}$ (Fig. 4). The tornado hit the city of Talsi, which was the place most affected by the tornado despite the fact its intensity was about F0-F1 at this point, according to reports of eye witnesses.

\subsection{Tornado in Poland, July 14, 2012}

The weather conditions of the tornado occurrence in Poland, only two weeks prior to the tornado in Latvia, were different. On July 14, 2012, Western and Central Europe was under the influence of a shallow low pressure area with its centre over Norway $(995 \mathrm{hPa})$, while the eastern part of the continent was covered by a high with its centre over Russia. Poland remained in the warm sector of the secondary low from over Denmark, which featured quite a warm maritime-polar air mass. The undulated line of cold front covering Germany in the morning hours was to move over the area of Poland in the afternoon (Fig. 5).

In the lower and central troposphere, nearly the whole of Europe was under the influence of a wide trough from the Norwegian Sea. The temperature at the $850 \mathrm{hPa}$ varied from $6^{\circ} \mathrm{C}$ to $8^{\circ} \mathrm{C}$, while the maritime-polar air mass, following the cold front, was slightly colder - by only $3^{\circ} \mathrm{C}$ to $4^{\circ} \mathrm{C}$. Thus, it is even difficult to distinguish on the map where the frontal lines and warm sector were (Fig. 6.)

The NWP analysis of the July 14, 2012, morning forecast materials did not show many factors indica- 
ting the occurrence of such an extreme weather phenomenon as a tornado within just a few hours. As mentioned above, the relatively warm maritime-polar air mass struggling over Poland on that day was not significantly unstable or humid - something that would be warning signal for intense convective phenomena, as was the case with the tornado in Latvia. Thermal conditions were quite "average" for this season and the maximum temperature on that day reached values of $25^{\circ} \mathrm{C}$ in north-west Poland. Furthermore, the surface thermal contrast in the frontal zone was small, not exceeding $5^{\circ} \mathrm{C}$. However, there were some symptoms of potential conditions for tornado formation. The analysis of air mass humi-dity showed that in the lo-

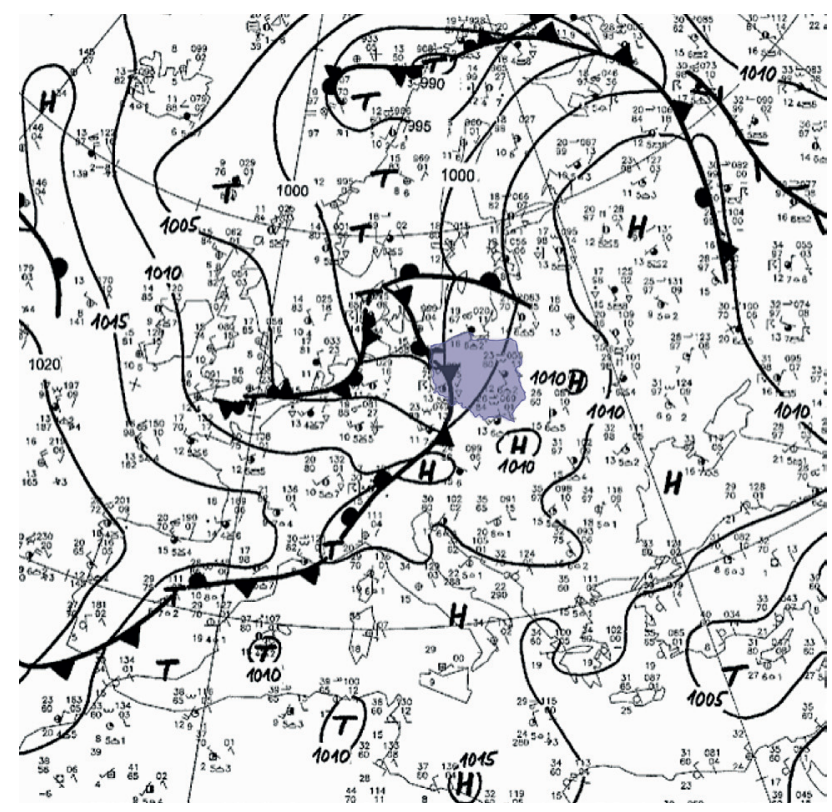

Fig. 5. The surface weather map; July 14, 2012; 12:00 UTC (source: DWD)

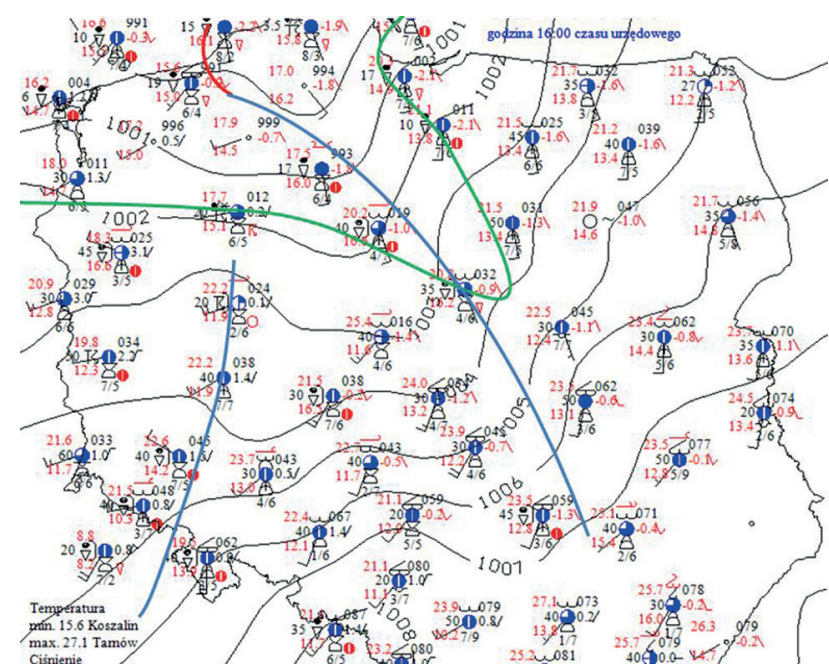

Fig. 6. The surface chart on July 14, 2012; 14:00 UTC. Blue lines show the cold fronts (main and secondary) while green line shows the area of higher humidity (dew points above $15^{\circ} \mathrm{C}$ ); source: Institute of Meteorology and Water Management, National Research Institute (IMGW-PIB) wer atmosphere, up to the altitude range of 2000-2500 m, the relative humidity was higher than $90 \%$, and the precipitable water (PW) indicator increased from $19 \mathrm{~mm}$ to $24 \mathrm{~mm}$. Atmospheric instability was identified as conditionally unstable. In the near ground layer of the atmosphere, up to $3000 \mathrm{~m}$, the air was characterized by low instability (CAPE: 200-600 J/kg according to nearby soundings from 12:00 UTC in Wrocław and Gdańsk) but it was relatively humid, while in the upper parts of the vertical profile of the atmosphere the air was dry with generally neutral stratification and was sepa-rated by an inversion layer present at the altitude of about $3000 \mathrm{~m}$ (Fig. 7.2). Such a vertical profile of the atmosphere usually causes the inversion layer to suppress the development of convective phenomena above the inversion level, unless it is "forced" as the result of the presence of an atmospheric front or another factor that releases this potential energy.

Another, and indeed the most significant factor that should have caused concern for a forecaster on duty in the afternoon of July 14, 2012, was the vertical wind profile. Both a wind veer in the layer closest to the ground and a vertical speed shear in the middle troposphere were observed (Fig. 7.1, 7.2). The wind veer in the layer of up to $1 \mathrm{~km}$ was significant. Wind speed and direction at the ground level was $160^{\circ} / 5 \mathrm{kt}$, while in the $0-3 \mathrm{~km}$ layer it increased and turned to $240^{\circ} / 37 \mathrm{kt}$. As we know, helical environments, especially with veer in the lowest $1 \mathrm{~km}$, are very conducive conditions to producing the tornado genesis process (Davies-Jones 1984). Furthermore, also in the middle troposphere, a strong vertical shear was present so that, in the layer up to $5 \mathrm{~km}$, the wind speed increased further, by $15 \mathrm{kt}$, reaching the speed of $50 \mathrm{kt}$. These conditions, conducive to the development of horizontal vorticity in the lower troposphere and wind shear favourable for vortex tube formation in the atmosphere, created a solid basis for the development of a mesocyclone of supercell (Kerr, Darkow 1996; Wurman, Kosiba 2013).

However, as mentioned earlier, the conditions for the development of strong convection currents in the morning of this day were not favourable and, for that reason, the phenomena occurring in the cold front zone, which in the afternoon started to move from north-west Poland towards the east, showed relatively little activity. The first thunderstorms were noted after 10:00 UTC and they were accompanied by light rain showers and wind gusts not exceeding $11-13 \mathrm{~m} / \mathrm{s}$. The intensification of convective phenomena occurred only in the north part of Poland in the late afternoon when convective activity had been strengthened by the influence of the upper level divergence connected with the jet stream movement over central Poland and the convective day-lift (Fig. 8.1). During the afternoon, the loca- 


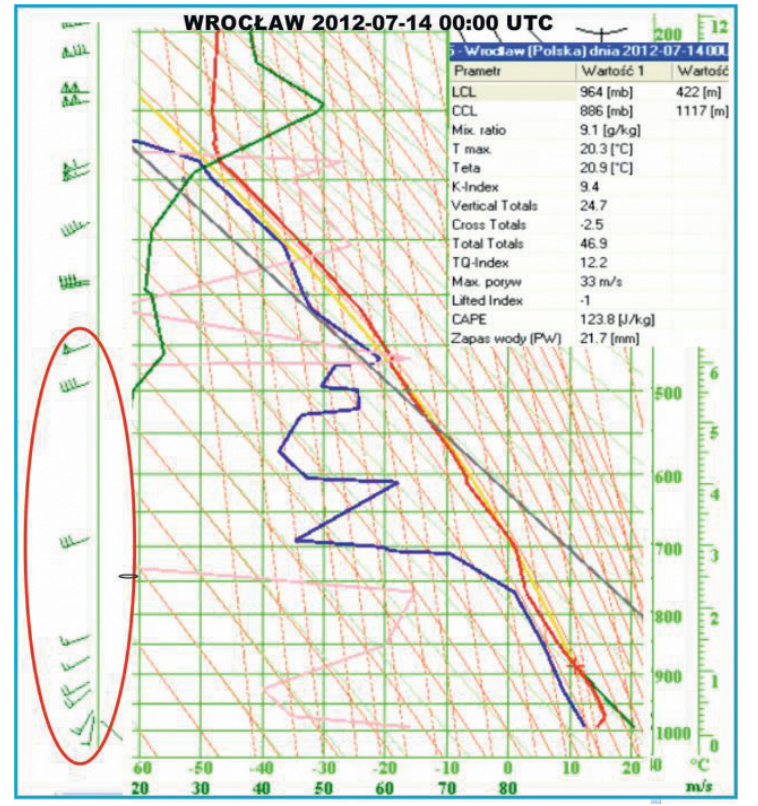

Fig. 7.1. Sounding from Wroclaw on July 14, 2012, 00:00 UTC. Red ellipse highlights vertical wind profile (source: IMGW-PIB)

tion of the jet stream over Poland was such that its northwest part was below the left-exit of the jet, and therefore, divergence in the upper troposphere caused the outflow of air in the upper layers of the troposphere, thus strengthening the vertical air movements below. At the $300 \mathrm{hPa}$ level, the increase of air divergence could be seen clearly between 06:00 UTC and 12:00 UTC - this confirms the described conditions (Fig. 8.1). Interestingly the temperature of the average $\mathrm{CB}$ tops at this afternoon oscillated just below $-50^{\circ} \mathrm{C}$, which indicates that the $\mathrm{CB}$ tops were at the height of about 6-8 $\mathrm{km}$ (this was obtained both from radar and satellite images). There were no overshooting tops visible, even during the highest convective activity through all the time the cold front passed across the area of Poland (Fig. 8.2).

However, the supercell's top towered 3-4 km above the tops of the surrounding clouds and reached a height of between 11-12 km. We can see its peak on the MAX CAPPI (Maximum Constant-Altitude Plan Position Indicator) radar reflectivity at 15:30 on July 14, 2012 (Fig. 9.1). The

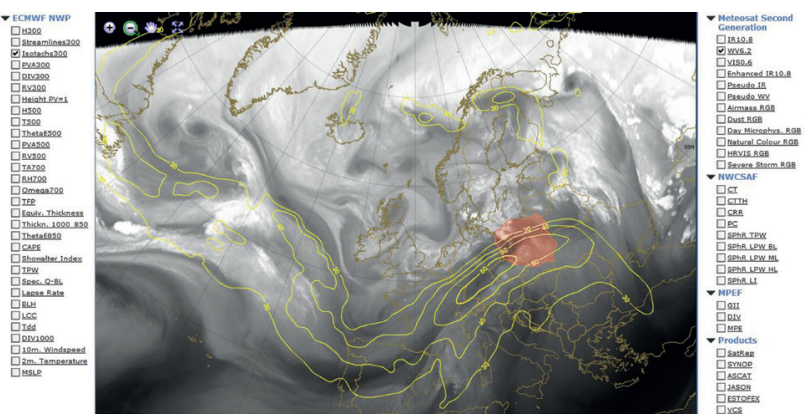

Fig. 8.1. Isotachs (yellow lines) and divergence (blue points) at $300 \mathrm{hPa}$ level; WV 6.2 image, July 14, 2012, 12:00 UTC (source: EUMeTrain)

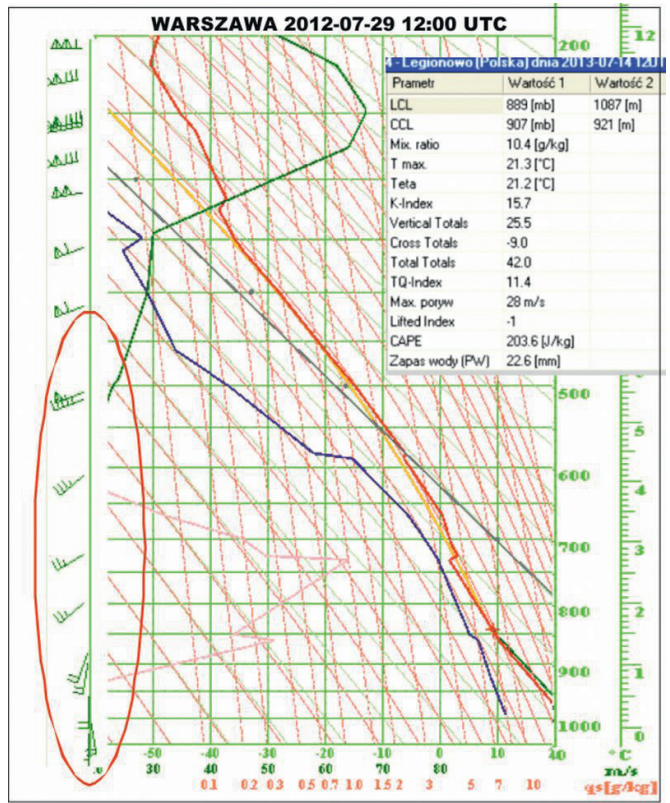

Fig. 7.2. Sounding from Warsaw on July 29, 2012, 12:00 UTC. Red ellipse highlights vertical wind profile (source: IMGW-PIB)

PPI (Plan Position Indicator) radar imagery shows cumulonimbus $(\mathrm{Cb})$ clouds with the "hook echo" which was associated with a mesocyclone and indicated favourable conditions for tornado formation over Warmia and Pomerania at around 15:30 UTC, as registered by the radar located in Gdańsk (Fig. 9.2).

Thus, even with the knowledge that the wind shear conditions were so favourable to tornado genesis supported by the upper-level jet, it is surprising that these weak convective circumstances created such an interaction between the environment and the $\mathrm{Cb}$ cloud, which resulted in the formation of a column of whirling air mass moving within a $7-8 \mathrm{~km}$ long, and ca. $300 \mathrm{~m}$ wide (Fig. 10) belt (causing the greatest damage in the villages of Stara Rzeka and Łączek in the Pomeranian Voivodeship, NW Poland).

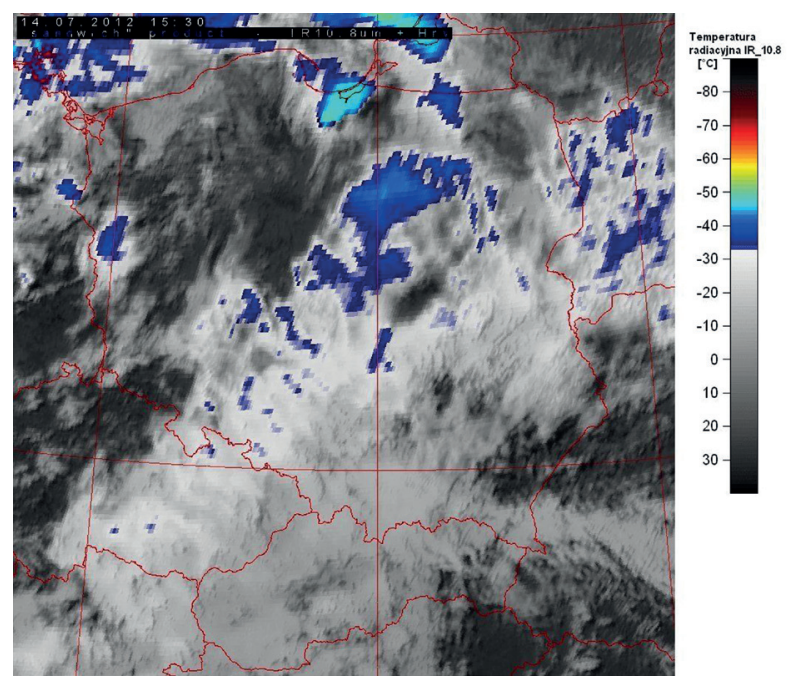

Fig. 8.2. "Sandwich" satellite indicates a temperature of top clouds over Poland and The Czech Republic; 14, 2012, 15:30 UTC (source: IMGW-PIB) 


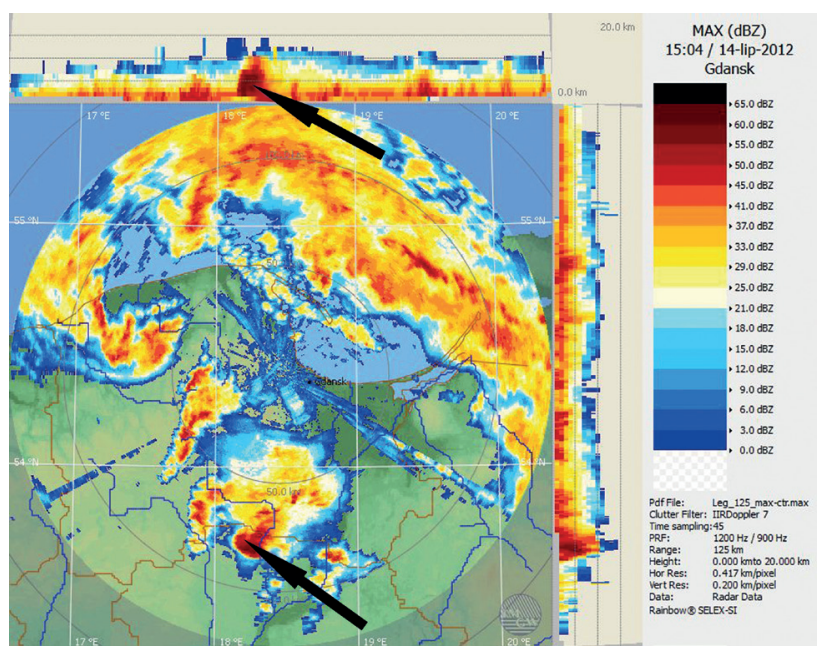

Fig. 9.1. MAX CAPPI image on 14 July 2012 at 15:34 in Gdańsk, Poland. The arrow shows the position of supercell (source: IMGW-PIB)
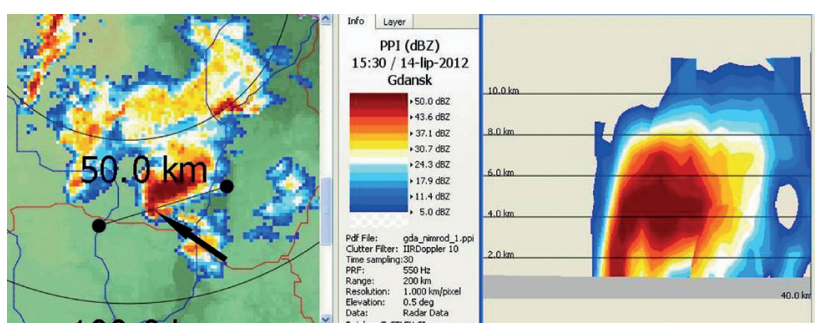

Fig. 9.2. PPI image on 14 July 2012 at 15:30 in Gdańsk, Poland that shows hook echo (indicated by an arrow) and vertical crosssection of supercell (source: IMGW-PIB; Irena Tuszyńska)

\section{Results and Discussion}

The synoptic situations presented here of tornado occurrences in Poland (July 14, 2012) and in Latvia (July 29, 2012) were different in terms of origin, but the impact they resulted in was catastrophic in both cases. Some of the numerous reports from the media and the ESWD (European Severe Weather Database) gave information about damage done by the Polish tornado: 1 fatality, 4 injured people, some roofs lost, Bory Tucholskie Forest was seriously damaged (Fig. 10). The worst damage (F2-F3

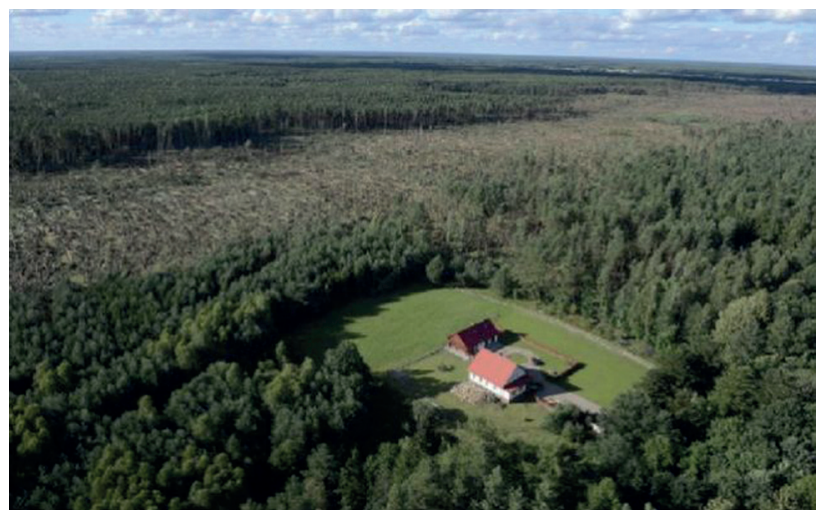

Fig. 10. The path of the tornado and damage done to the forestry (fot. K. Kowalski/FORUM) category) was reported in Smętowo Graniczne. The tornado in Latvia (F0-F1 category) hit the city of Talsi, causing local damage in the city centre and two fatalities due to flying roof parts and a falling tree. About 10000 houses were also left with no electricity.

In both cases, the cause that triggered the updraft in the atmosphere was the cold front zone. However, in Poland its activity was relatively weak, while in Latvia the convergence line that preceded the front zone was very active and the tornado occurrence that preceded two hours before the main front was connected just with its activity. Another common feature of both cases was the presence of the upper-level jet. It is known to focus primarily in the lower troposphere in cases of tornado occurrence, however, the influence of upper and middle flow on the low level storm relative flow and storm relative helicity is significant (Droegemeier et al. 1993; Kerr, Darkow 1996). The westnorth area of Poland on that afternoon was under the rightentrance jet in the area of increased upper-level divergence, while the left-exit covered Latvia.

The crucial difference between these two weather events seems to be the thermodynamic conditions in the troposphere for creating of a favourable environment for tornadic thunderstorm. In the Polish case, the thermal circumstances were quite weak, with a low environmental CAPE (below 200-600 J/kg) that did not lead to strong convective updraft. However, the environmental vertical wind shear profile, amplified by the upper-level jet, prepared the perfect condition for tilting and rotation in the low/middle troposphere, and this produced the vortices (Rotunno 1981; Davies-Jones 1984). The veer in the layer up to $1 \mathrm{~km}$ was significant. Wind at the ground level $160^{\circ} / 5 \mathrm{kt}$ increased and turned to $240^{\circ} / 37 \mathrm{kt}$ in the $0-3 \mathrm{~km}$ layer. The relationship between storm structure and the environmental storm-relative flow resulted in the creation of a mesocyclone that yielded in tornado transition (Weisman, Klemp 1982; Lilly 1986a, b). It seems accurate to suppose that just this strong interaction between the environmental storm-relative flow and the relatively weak $\mathrm{Cb}$ updraft led to its transformation into a tornadic supercell structure, which was the basic reason for tornado occurrence in Poland.

In Latvia the situation was totally different. This tornado developed in a humid and very hot air mass of tropical origin. The specific humidity of the warm sector of an air mass that struggled over Latvia was very moist, and oscillated between 12 and $15 \mathrm{~g} / \mathrm{kg}$, which corresponded to a mean precipitation water content (PW) of about $40 \mathrm{~mm}$ ( $\max \mathrm{PW}=44 \mathrm{~mm}$ ). Convective available potential energy (CAPE) increased on the morning up to $2200 \mathrm{~J} / \mathrm{kg}$, and the values of lifted index (LI) were also high: $-5^{\circ} \mathrm{C}$. Convec- 
tive inhibition energy (CIN) decreased totally from $-87 \mathrm{~K} /$ $\mathrm{kg}$ during the 12 hours preceding the occurrence of the tornado, which suggests that strong enough static stability in the morning was overcome by high instability during the day, supported by the approaching convergence line. The favourable conditions for deep convection resulted in the formation of supercell the bases of which began at $300 \mathrm{~m}$ (LCL about $280 \mathrm{~m} \mathrm{AGL}$ ) and expanded through the tropopause into the lower stratosphere in the form of overshooting tops higher than $15 \mathrm{~km}$ (Fig. 4 ). The environmental wind profile also showed the proper hodograph clockwise curvature for a supercell (from 090\%05 kt near the surface to $220^{\circ} / 25 \mathrm{kt}$ at about $2000 \mathrm{~m}$ height). This wind shear was strong enough to provide two distinctive kinds of thunderstorm - multicell and supercell. The latter developed in the convergence line, quickly developed above the troposphere, then weakened and disappeared. All this process occurred in no longer that one hour. The multicell structures appeared in the cold front zone about two hour later. They were also characterized by very strong reflectivity detected by the weather radar located at Riga airport. Thus, inside the land hail (2-4 cm size) strong wind gusts and downdrafts of these huge $\mathrm{Cb}$ multicells caused damage of even the same severity as that caused by a tornado. This was because the huge potential energy of the updrafts was converted into the kinematic energy of the horizontal wind.

\section{Bibliography}

Agee E., Jones E., 2009, Proposed conceptual taxonomy for proper identification and classification of tornado events, Weather and Forecasting, 24 (2), 609-617, DOI: 10.1175/2008WAF2222163.1

Boustead J.M., Mayes B.E., Gargan W., Leighton J.L., Phillips G., Shumacher P.N., 2013, Discriminating environmental conditions for significant warm sector and boundary tornadoes in parts of the Great Plains, Weather and Forecasting, 28 (6), 1498-1523.

Brazdil R., Chroma K., Dobrovolny P., Černoch Z., 2012, The tornado history of the Czech Lands, AD 1119-2010, Atmospheric Research, 118, 193-204, DOI: 10.1016/j.atmosres.2012.06.019

Brooks H., Doswell C.A. III, 2001, Some aspects of the international climatology of tornadoes by damage classification, Atmospheric Research, 56 (1-4), 191-201, DOI: 10.1016/ S0169-8095(00)00098-3

Corfidi S.F., Weiss S.J, Kain J., Corfidi S., Rabin R., Levit J., 2010, Revisiting the 3-4 April 1974 super outbreak of tornadoes, Weather and Forecasting, 25 (2), 465-510, DOI: 10.1175/2009WAF2222297.1
Davies-Jones R., 1984, Streamwise vorticity: The origin of updraft rotation in supercell storms, Journal of the Atmospheric Sciences, 41 (20), 2991-3006, DOI: 10.1175/1520-0469(1984)041<2991:SVTOOU>2.0.CO;2

Davies-Jones R., 2006, Tornado genesis in supercell storms what we know and what we don't know? Preprints $86^{\text {th }}$ AMS Annual Meeting, Atlanta, USA, available at https://ams.confex.com/ams/pdfpapers/104563.pdf (data access 26.05.2015)

Doswell C.A. III., 1987, The distinction between large-scale and mesoscale contribution to severe convection. A case study example, Weather and Forecasting, 2 (1), 3-16, DOI: 10.1175/1520-0434(1987)002<0003:TDBLSA >2.0.CO;2

Dotzek N., 2003, An updated estimate of tornado occurrence in Europe, Atmospheric Research, 67-68, 153-161, DOI: 10.1016/S0169-8095(03)00049-8

Droegemeier K.K., Lazarus S.M., Davies-Jones R., 1993, The influence of helicity on numerically simulated convective storms, Monthly Weather Review, 121 (7), 2005-2029, DOI: 10.1175/1520-0493(1993)121<2005:TIOHON>2.0.CO;2

Gold D.A., Nielsen-Gammon J.W., 2008, Potential vorticity diagnosis of the severe convective regime. Part III: The Hesston tornado outbreak, Monthly Weather Review, 136 (5), 1593-1611, DOI: 10.1175/2007MWR2092.1

Houze R.A., 1993, Cloud dynamic, Junior Academic Press, USA, 573 pp.

Kerr B.W., Darkow G.L., 1996, Storm-relative winds and helicity in the tornadic thunderstorm environment, Weather Forecast, $11,489-505$

Lilly D.K., 1986a, The structure, energetics, and propagation of rotating convective storms. Part I: Energy exchange with the mean flow, Journal of the Atmospheric Sciences, 43 (2), 113125, DOI: $10.1175 / 1520-0469(1986) 043<0113$ :TSEAPO $>2.0 . \mathrm{CO} ; 2$

Lilly D.K., 1986b, The structure, energetics, and propagation of rotating convective storms. Part II: Helicity and storm stabilization, Journal of the Atmospheric Sciences, 43 (2),126140, DOI: $10.1175 / 1520-0469(1986) 043<0126$ :TSEAPO $>$ 2.0.CO;2

Maddox R.A., Doswell C.A. III, 1981, An examination of jet stream configuration, $500 \mathrm{mb}$ vorticity advection and low level thermal advection patterns during extended periods of intense convection, Monthly Weather Review, 110 (3), 184-197, DOI: 10.1175/1520-0493(1982)110<0184:AEOJSC $>2.0 . C O ; 2$

Maddox R.A., Hoxit L.R., Chappell C.F., 1980, A study of tornadic thunderstorm interactions with thermal boundaries, Monthly Weather Review, 108 (3), 322-336, DOI: 10.1175/1520-0493(1980)108<0322:ASOTTI >2.0.CO;2

Marcinoniene I., 2003, Tornadoes in Lithuania in the period of 1950-2002 including analysis of the strongest tornado of 29 May 1981, Atmospheric Research, 67-68, 475-484, DOI: 10.1016/S0169-8095(03)00060-7 
Mercer A.E., Shafer C.M., Doswell C.A. III, Leslie L.M, Richman M.B., 2012, Synoptic composites of tornadic and nontornadic outbreaks, Monthly Weather Review, 140 (8), 25902608, DOI: 10.1175/MWR-D-12-00029.1

Rauhala I., Brooks H., Szchultz D.M., 2012, Tornado Climatology of Finland, Monthly Weather Review, 140, 1446-1456, DOI: 10.1175/MWR-D-11-00196.1

Rotunno R., 1981, On the evolution of thunderstorm rotation, Monthly Weather Review, 109 (3), 577-586, DOI: 10.1175/1520-0493(1981)109<0577:OTEOTR >2.0.CO;2

Rotunno R., Klemp J.B., 1982, The influence of the shearinduced pressure gradient on thunderstorm motion, Monthly Weather Review, 110 (2), 136-151, DOI: 10.1175/1520-0493(1982)110\%3C0136:TIOTSI\%3E2.0. $\mathrm{CO} ; 2$.

Schaefer J.T., Doswell C.A. III, 1984, Empirical orthogonal function expansion applied to progressive tornado outbreaks, Journal of the Meteorological Society of Japan, 62 (6), 929-936

Schumann M.S., Roebber P.J., 2010, The influence of uppertropospheric potential vorticity on convective morphology, Monthly Weather Review, 138 (2), 463-474, DOI: 10.1175/2009MWR3091.1
Setvák M., Šálek M., Munzar J., 2003, Tornadoes within the Czech Republic: from early medieval chronicles to the "internet society", Atmospheric Research, 67-68, 589-605, DOI: 10.1016/S0169-8095(03)00075-9

Uccelini L.W., Johnson D.R., 1979, The coupling of upper and lower tropospheric jet streaks and implication for the development of severe convective storms, Monthly Weather Review, 107 (6), 682-703, DOI: 10.1175/1520-0493(1979)107<0682:TCOUAL >2.0.CO;2

Weisman M.L., Klemp J.B., 1982, The dependence of numerically simulated convective storms on vertical wind shear and buoyancy, Monthly Weather Review, 110 (6), 504-520, DOI: 10.1175/1520-0493(1982)110<0504:TDONSC >2.0.CO;2

Wurman J., Kosiba K., 2013, Finescale radar observations of tornado and mesocyclone structures, Weather and Forecasting, 28 (5), 1157-1174, DOI: 10.1175/WAF-D-12-00127.1

Wurman J., Kosiba K., Markowski P., Richardson Y., Dowell D., Robinson P., 2010, Finescale single- and dual-doppler analysis of tornado intensification, maintenance, and dissipation in the Orleans, Nebraska, Supercell., Monthly Weather Review, 138 (12), 4439-4455, DOI: 10.1175/2010MWR3330.1 